\title{
Iron-chrome-aluminum alloy cladding for increasing safety in nuclear power plants
}

\author{
Raul B. Rebak* \\ GE Global Research, 1 Research Circle, Schenectady, NewYork 12309, USA
}

Received: 10 June 2017 / Received in final form: 25 September 2017 / Accepted: 7 November 2017

\begin{abstract}
After a tsunami caused plant black out at Fukushima, followed by hydrogen explosions, the US Department of Energy partnered with fuel vendors to study safer alternatives to the current $\mathrm{UO}_{2}$-zirconium alloy system. This accident tolerant fuel alternative should better tolerate loss of cooling in the core for a considerably longer time while maintaining or improving the fuel performance during normal operation conditions. General electric, Oak ridge national laboratory, and their partners are proposing to replace zirconium alloy cladding in current commercial light water power reactors with an iron-chromium-aluminum (FeCrAl) cladding such as APMT or C26M. Extensive testing and evaluation is being conducted to determine the suitability of FeCrAl under normal operation conditions and under severe accident conditions. Results show that $\mathrm{FeCrAl}$ has excellent corrosion resistance under normal operation conditions and $\mathrm{FeCrAl}$ is several orders of magnitude more resistant than zirconium alloys to degradation by superheated steam under accident conditions, generating less heat of oxidation and lower amount of combustible hydrogen gas. Higher neutron absorption and tritium release effects can be minimized by design changes. The implementation of FeCrAl cladding is a near term solution to enhance the safety of the current fleet of commercial light water power reactors.
\end{abstract}

\section{Introduction}

Nuclear power plants are one of the most reliable and cleaner ways of producing electricity. Approximately 450 commercial nuclear power plants are used in 30 countries to produce low cost electricity [1]. At least 13 countries use nuclear power to supply about a quarter of their electricity [2]. In the USA alone, the use of nuclear power prevented in 2015 the release of 564 million metric tons of carbon dioxide to the environment [2]. Commercial nuclear power plants (NPP) are designed to be operated without significant effect on the public health and safety and effect on the environment [3]. The operation of NPP energy facilities do not emit greenhouse gases [2]. The main risk of operating a nuclear power plant is the release of radioactive elements into the environment, and for that reason, several barriers are constructed between the fuel containing the radioactive elements and the environment. The first barrier to protect the fuel is the hermetically sealed metallic cladding which envelops the pellets of uranium oxide. That is, maintaining the integrity of the cladding is the first crucial containment for the radioactive material. Further barriers include the

\footnotetext{
* e-mail: rebak@ge.com
}

reactor pressure vessel, the concrete building structure containing the pressure vessel and abundant amounts of water that remove the heat from the nuclear reaction [3].

The Nuclear regulatory commission of the USA uses probabilistic risk assessment methods to assess the likelihood and consequences of severe reactor accidents in accordance with the code of federal regulations 10 CFR 50.109 [3]. The Risk $\mathrm{R}$ is defined as a function of scenarios Si that can go wrong, of how likely the scenario will happen (frequency fi), and of the consequence $\mathrm{Ci}$ of the scenario, $\mathrm{Si}$ (Eq. (1)) [4].

$$
R=\{S i, \quad f i, \quad C i\} .
$$

The notion of risk includes both opportunities and threats. The basis of managing risk is to build multiple barriers between the threats that can lead to an adverse event of, for example, an operating a nuclear reactor. In the case of the Fukushima disaster of March 2011, the low frequency and high consequence event of the tsunami caused the destruction of the diesel generators that provided the emergency power to pump the water to cool the fuel rods in the reactor and in the cooling pools. Consequently, water and steam reacted rapidly with the zirconium material of the fuel cladding above $400^{\circ} \mathrm{C}$ producing large amounts of heat and hydrogen (Eq. (2)) that were vehicles for the release of some radioactivity into the environment. 


\section{Political Conditions}

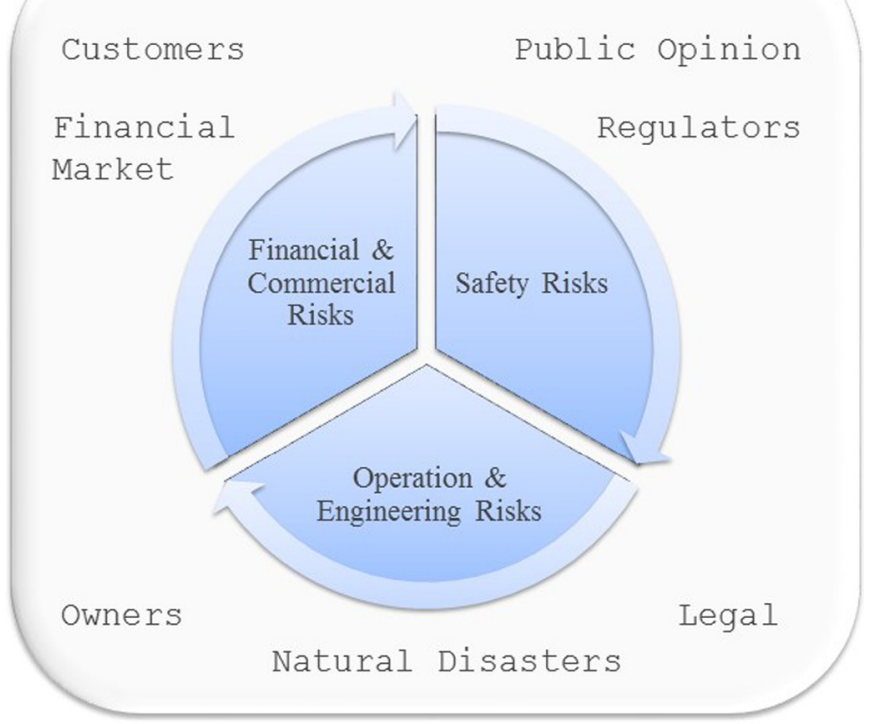

Fig. 1. Risk management environment model for a nuclear power plant operator. The aim of the GE-ORNL team is to minimize engineering risks by using $\mathrm{FeCrAl}$ cladding.

$$
\mathrm{Zr}+2 \mathrm{H}_{2} \mathrm{O}=\mathrm{ZrO}_{2}+\mathrm{H}_{2}+\text { Heat } .
$$

Once the zirconium metal cladding was consumed by steam, the radioactive fuel was released inside the second barrier, the thick-walled steel reactor pressure vessel. That is, the effect of the tsunami in Fukushima was to destroy the first barrier or the metallic zirconium cladding containing the radioactive elements. To minimize the risk of failure of the operating nuclear power plant, a stronger first barrier should be constructed between the fuel and the second barrier, and eventually from the environment.

\section{Risk management in a nuclear power plant environment}

Benefits from risk management in a nuclear power plant do not only include safety scenarios but also production (operational or engineering) and economics (financial) scenarios [5] (Fig. 1). Each one of these risk disciplines will incorporate their own frequencies and consequences. Another discipline or scenario that can be added is the strategic one, which covers things like type of government in the country, nationalization or expropriations, public perception, regulatory and legal framework, etc. (represented as the larger square in Fig. 1). It is important to identify all the consequences of an event (e.g. tsunami) to be able to minimize adversarial outcomes and to maximize public response and commercial gains in a cost-efficient manner [5]. The risk management framework is an iterative process in which first the possible risks are identified (together with potential consequences and relative impact of each consequence), then the techniques to manage the risk are identified (e.g. risk reduction or risk transfer), and finally the chosen strategies or techniques are imple- mented. This process is followed by monitoring and feedback to determine the effectiveness of the solutions and, if necessary, repeat the process with other improved measures. For example, risk reduction can be accomplished by engineering changes, organizational changes, staff training, etc. and risk transfer can be implemented by contracts with suppliers, insurance, regulation, etc.

Following the example from the Fukushima incident, one way of reducing risk in plant operation would be the engineering replacement of zirconium alloys from the nuclear fuel of the power plant with $\mathrm{FeCrAl}$ alloys. This is an obvious technical change that would greatly reduce the consequence of the explosion that considerably affected the public perception of safe operation of nuclear power plants. That is, the use of $\mathrm{FeCrAl}$ alloys can only produce opportunities to reduce the engineering risk identified in Figure 1. The $\mathrm{FeCrAl}$ alloy is the first barrier between the radioactive elements and the biosphere surrounding the NPP. By improving on the performance of the first barrier (cladding of the fuel), the consequence of combustible hydrogen explosion or release of radioactive elements outside the NPP is greatly minimized.

\section{Accident tolerant fuels (ATF)}

Because of the Fukushima accident of March 2011, the US Department of Energy (DOE) has a mandate from US Congress to develop accident tolerant fuels under cost sharing programs with the nuclear fuel vendors [6-8]. Today many prefer to call the Accident tolerant fuel (ATF) as Advanced technology fuel (ATF). A fuel may be defined as having enhanced accident tolerance if, in comparison with the current $\mathrm{UO}_{2}$-zirconium alloy system, it can tolerate loss of active light water cooling in the reactor core for a considerably longer time (called coping time) while maintaining or improving fuel performance during normal operations and operational transients, as well as in design basis and beyond design-basis events. The enhanced fuel material should have

- improved reaction kinetics with steam;

- slower hydrogen production rate;

- improved cladding and fuel properties;

- enhanced retention of fission products.

The DOE provided a five-step guideline or metrics to assess the behavior of the ATF concept (Fig. 2) [9]. That is, the concept for accident tolerant fuel rods must be able to perform as well as the current system under normal operation conditions in the order of $300-400{ }^{\circ} \mathrm{C}$ cladding temperature (Step 1). This includes low corrosion rates in both boiling water reactors (BWR) and pressurized water reactor (PWR) environments, no environmental assisted cracking, no shadow corrosion, no hydriding that will render the rod brittle, no fretting or debris damage, etc. (Step 1). Also in Step 1, it needs to be demonstrated that the new fuel will be compatible with the thermal and hydraulic flow inside of the reactor. Step 2 requires that the ATF fuel rod would be better than the current zirconium uranium dioxide system under design basis accidents including the temperature range between 400 and $1200^{\circ} \mathrm{C}$ 


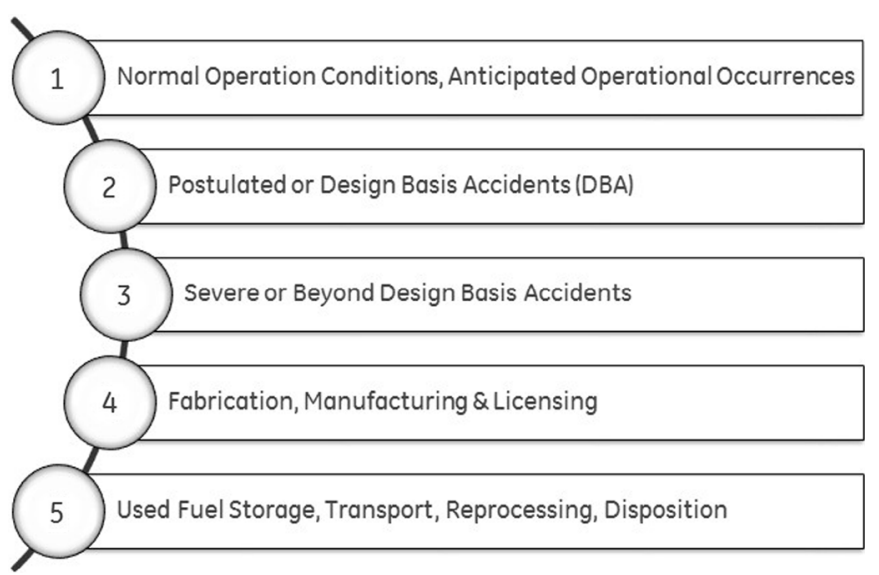

Fig. 2. Five metric Areas Provided by DOE to Evaluate ATF [9].

of the cladding temperature in contact with the coolant. Step 3 requires that under severe accident conditions $\left(T>1200^{\circ} \mathrm{C}\right)$, the cladding would be superior to the current system, for example by tolerating reaction with steam to produce lower amounts of heat and explosive hydrogen gas [10]. Step 4 requires that the new ATF fuel rod can be manufactured easily using economical and standard procedures such as tube fabrication and hermetical welding or sealing. Moreover, Step 4 covers the changes that are required in the regulators or licensing specifications (e.g. Nuclear regulatory commission in the US) that would allow for the new ATF rod to be deployed into a commercial light water reactor. Step 5 is concerned about the condition of the fuel rods after their useful life in the reactor, if the bundles can be safely and integrally removed from the reactor to be securely stored in cooling pools for a period of 5 years or more, and how the rods will perform under dry cask storage for periods in the order of 100 years, before final disposition in a nuclear waste repository or reprocessing of the used fuel [9].

The objective of the GE project is to develop an ironchromium-aluminum ( $\mathrm{FeCrAl}$ ) fuel cladding for current design light water power reactors. The idea of using $\mathrm{FeCrAl}$ alloys as cladding for current $\mathrm{UO}_{2}$ fuel is also supported by Oak ridge national laboratory (ORNL), who developed the alloy C26M. Besides Fe, Cr, and Al, the cladding may contain other elements such as molybdenum, yttrium, hafnium, zirconium, etc. The composition of choice is $\mathrm{Fe}+(10-22) \mathrm{Cr}+(4-6) \mathrm{Al}+(2-3) \mathrm{Mo}+$ traces of $\mathrm{Y}, \mathrm{Hf}$, $\mathrm{Zr}$, etc. The FeCrAl cladding concept is a near term solution for providing enhanced safety to the current fleet of light water reactors. The main reason $\mathrm{FeCrAl}$ has been selected is because it has superior oxidation resistance in the event of a severe accident. Figure 3 shows the process of how this alloy resists attack by superheated steam. Under normal operation conditions and up to $1000^{\circ} \mathrm{C}$ the protection to the alloy is given by the formation of a chromium rich oxide on the surface. However, as the temperature increases beyond $1000^{\circ} \mathrm{C}$, an aluminum oxide layer (alumina) forms between the metal and the chromium oxide layer. Eventually, in the presence of steam, the chromium oxide layer volatilizes and the alumina layer remains on the surface protecting the alloy from further oxidation up to its melting point $\left(\sim 1500^{\circ} \mathrm{C}\right)$. Figure 4 shows the presence of a one micron thick layer of alumina on the surface of APMT coupon after exposure for $2 \mathrm{~h}$ at $1200^{\circ} \mathrm{C}$ in $100 \%$ steam.

$\mathrm{FeCrAl}$ has excellent environmental resistance characteristics under normal operation both for boiling and pressurized water reactors (BWR and PWR) coolants. There is no need to change the water chemistry of the BWR and PWR light water coolants since FeCrAl is compatible with the existing water chemistries. The use of $\mathrm{FeCrAl}$ would eliminate common/current fuel failure mechanisms such as fretting and shadow corrosion. There is no change in fuel type since the $\mathrm{GE} \mathrm{FeCrAl} \mathrm{concept} \mathrm{utilizes} \mathrm{the}$ present $\mathrm{UO}_{2}$ fuel. The current $\mathrm{FeCrAl}$ alloy candidates are APMT and C26M, the latter being an optimization alloy composition with lower $\mathrm{Cr}$ to avoid embrittlement under irradiation. Fabrication studies continue at ORNL and GE. ORNL and GE have been conducting research in the five areas listed in Figure 2 since 2012. The aim of this document is to describe the maturity of the FeCrAl concept and the overall feasibility on the use of ferritic $\mathrm{FeCrAl}$ alloys as cladding for nuclear fuel in commercial light water reactors. GE and ORNL are following a methodical approach to evaluate metrics or performance attributes outlined by Bragg-Sitton et al. [9]. Many other countries such as China, Japan, Korea, Belgium, etc. are also developing ATF fuel based on FeCrAl.

It is noted that austenitic stainless steel (SS) materials were used for fuel rod cladding in the past both for US commercial plants and overseas NPP [11]. Preliminary studies on FeCrAl alloy materials indicate sufficient strength and ductility to perform acceptably as cladding alloy, like past use of austenitic SS cladding. FeCrAl alloys do not contain nickel, which is a more expensive and a higher neutron absorption element than Fe, $\mathrm{Cr}$ or $\mathrm{Al}$. However, compared to the negative experience with austenitic SS cladding, extensive crack propagation studies in high temperature water showed that ferritic FeCrAl was several orders of magnitude more resistance to environmentally-assisted cracking than modern type 304 SS [7]. Because of its ferritic or bcc structure, $\mathrm{FeCrAl}$ alloys are also more resistant to irradiation degradation than prior versions of austenitic SS cladding materials. Proton irradiation studies performed at the U. of Michigan showed that $\mathrm{FeCrAl}$ materials may be resistant to proton irradiation induced cracking providing additional confirmation of the potential acceptability of $\mathrm{FeCrAl}$ materials for fuel rod cladding [12]. Although there may be nominal changes in fuel rod geometry (e.g. clad OD and thickness) for lead rod assembly designs and in fuel assembly designs (e.g. fuel channels design) to accommodate differences in material performance in future fuel designs, such changes are expected to be incremental to existing fuel rod and assembly designs, significantly leveraging the knowledge base for current fuel designs for the new concept. Simulation studies performed at Brookhaven National Laboratory showed that there is little or no impact on the thermal-hydraulic properties of the system by using a fuel rod clad with a FeCrAl alloy [13]. It is expected that a $\mathrm{FeCrAl}$ alloy clad fuel rod can be designed with minimal 


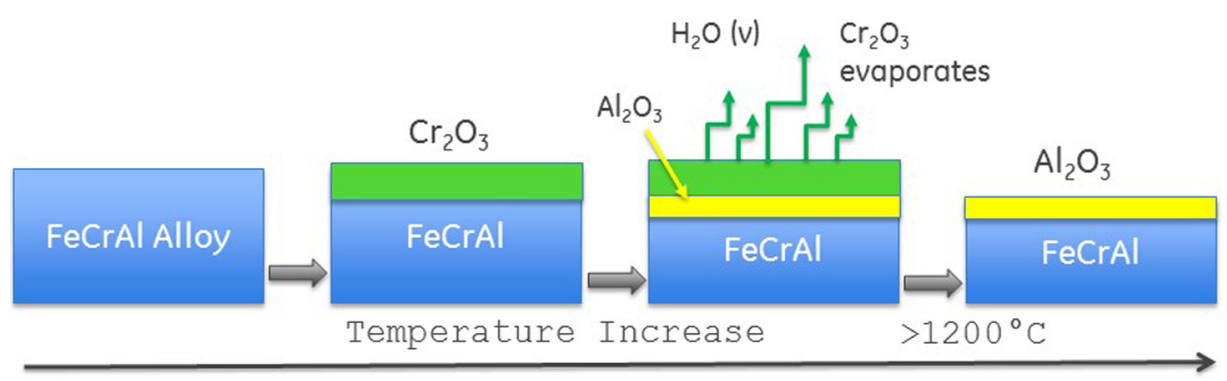

Fig. 3. Oxidation Behavior of FeCrAl in Super-Heated Steam.

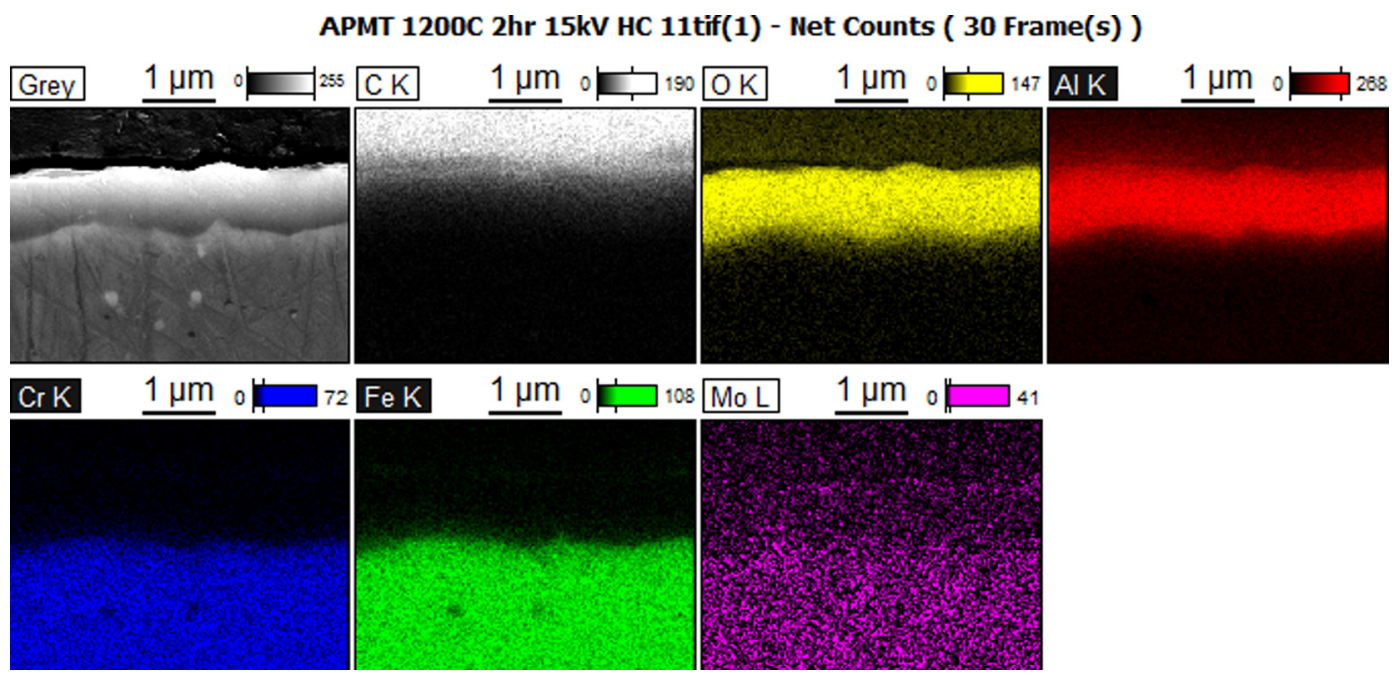

Fig. 4. Coupon of APMT exposed to $100 \%$ steam for $2 \mathrm{~h}$ at $1200^{\circ} \mathrm{C}$. A $1 \mu \mathrm{m}$-thick alumina layer is observed on it surface.
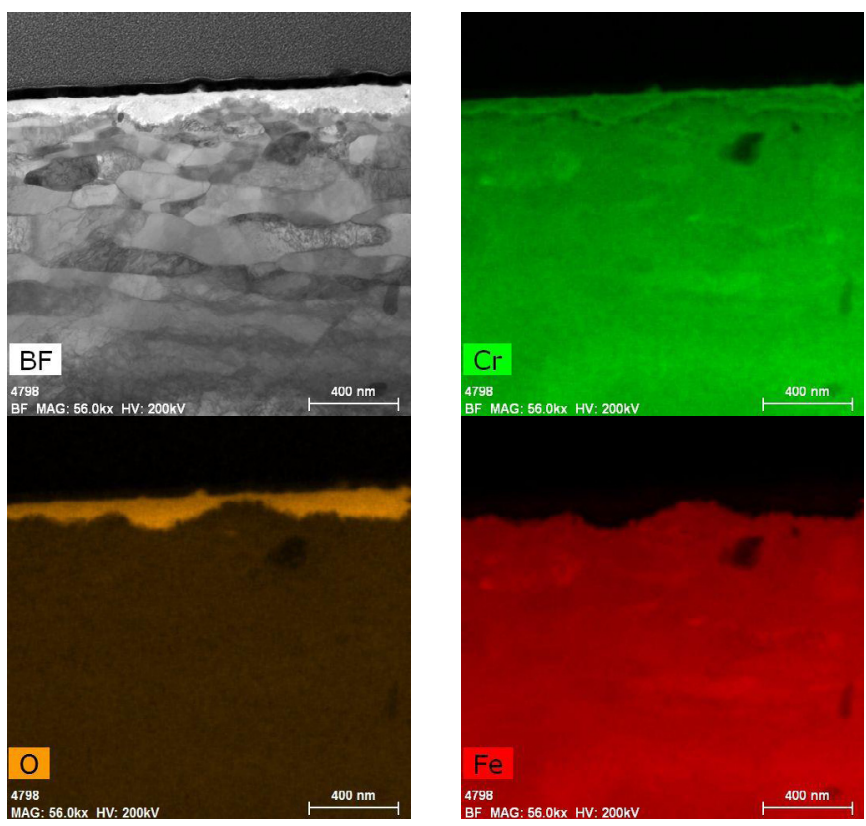

Fig. 5. Coupon of APMT exposed to PWR type water pure water $+3.75 \mathrm{ppm}$ hydrogen at $330^{\circ} \mathrm{C}$ for one year. A $\sim 150 \mathrm{~nm}$ oxide layer rich in $\mathrm{Cr}$ is observed on its surface. thermal-hydraulic design changes. FeCrAl alloy cladding is completely compatible with the current coolant chemistries used in either BWR or PWR reactors, that is, significant coolant chemistry changes are not expected because of $\mathrm{FeCrAl}$ implementation. Extensive immersion studies with chemistries typically observed in both BWR and PWR reactors showed excellent corrosion resistance of the $\mathrm{FeCrAl}$ alloys both under hydrogen and oxygen atmospheres [14,15]. Figure 5 shows a protective $\mathrm{Cr}$ rich layer protecting the surface of APMT while exposed for a year in PWR type environments containing dissolved hydrogen. This is the same behavior observed for other current structural reactor internal materials such as type 316 SS [16,17].

Electrochemical studies in high temperature water showed that $\mathrm{FeCrAl}$ have a behavior like traditional reactor alloys such as type $304 \mathrm{SS}$ and nickel based alloy X750. Electrochemical studies performed at GE Global Research showed that $\mathrm{FeCrAl}$ rods in contact with a separator grid of alloy X-750 would not experience galvanic corrosion under irradiation conditions [18], allowing utilization of current existing grid/spacer designs.

Japan and other countries are also participating in the development of $\mathrm{FeCrAl}$ alloys for fuel cladding $[19,20]$. 


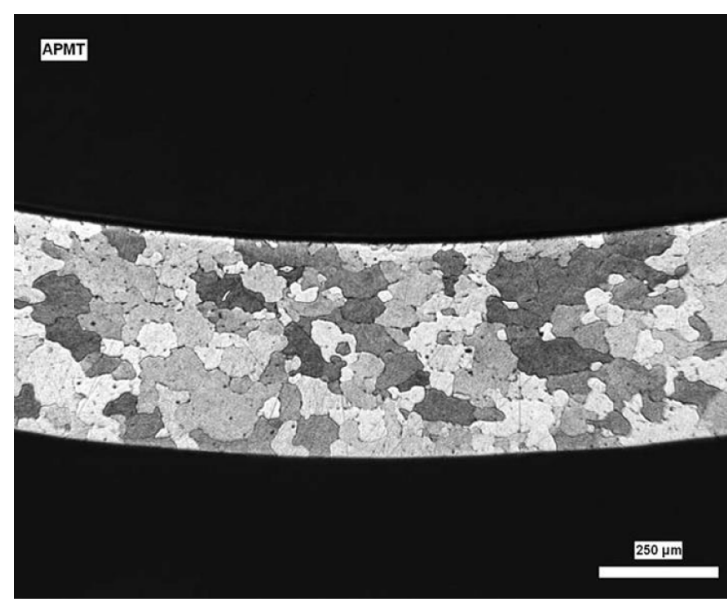

APMT

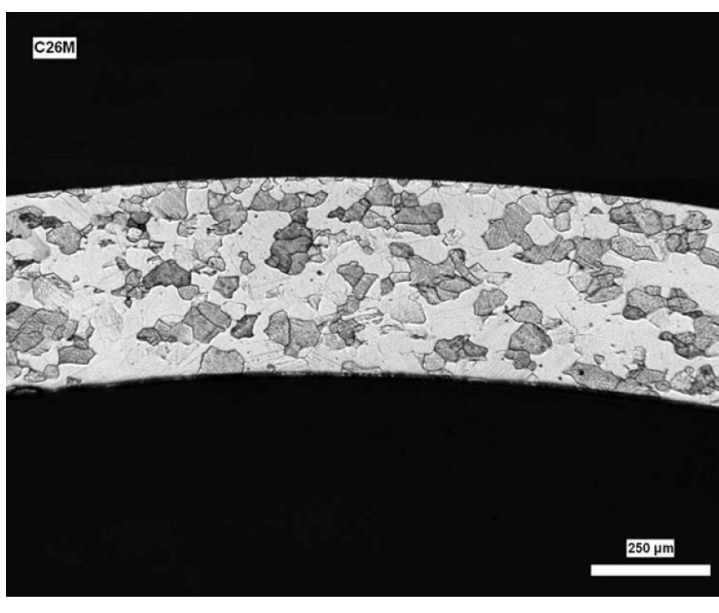

$\mathrm{C} 26 \mathrm{M}$

Fig. 6. Thin walled tubes of APMT and C26M fabricated using industrial practices. APMT is $\mathrm{Fe}+21 \mathrm{Cr}+5 \mathrm{Al}+3 \mathrm{Mo}$ and $\mathrm{C} 26 \mathrm{M}$ is $\mathrm{Fe}+12 \mathrm{Cr}+6 \mathrm{Al}+2 \mathrm{Mo}$.

\section{Fabrication, manufacturing and licensing}

The $\mathrm{FeCrAl} / \mathrm{UO}_{2}$ fuel rod is compatible with current large-scale production technology. Uranium dioxide $\left(\mathrm{UO}_{2}\right)$ pellet fabrication would remain the same as in the current process. Currently, tube fabrication trials are being conducted to demonstrate that $\mathrm{FeCrAl}$ alloys can be produced as long, thin walled tubes for fuel rod assemblies. Although the cladding fabrication process is yet untested for large scale production, there does not appear to be a significant barrier for production quantities of the cladding. Preliminary studies demonstrated $\mathrm{FeCrAl}$ compatibility with existing welding, manufacturing, and quality practices used with current Zircaloy based rod assembly systems. The fabrication processes for the $\mathrm{FeCrAl} / \mathrm{UO}_{2}$ system will be similar to the current LWR fuel fabrication processes (pilgering/extruding, heat treatments, welding, NDE techniques, etc.) which are mature and well understood. Figure 6 shows etched metallographic cross sections of APMT and C26M tubes made following industrial practices. Figure 7 shows initial welding trials at the industrial fuel plant of APMT thin wall tubes to the APMT end caps. No issues were encountered complying with current nuclear industry quality and performance standards.

$\mathrm{FeCrAl} / \mathrm{UO}_{2}$ fuel rod systems will have minimal or no impact in the handling of the fuel, shipping requirements and/or plant operations. It is expected that standard analyses techniques applied to zirconium alloy systems may be used substituting $\mathrm{FeCrAl}$-specific properties to demonstrate acceptable performance under shipping and handling conditions, although licensing for shipping of the LFR/LFAs will need to be completed as well as in-core licensing.

Originally the deadline for insertion of a LFA into a commercial reactor given by DOE was 2022 [9] but the GE team working with the US Nuclear regulatory commission and Southern nuclear is planning to have a first $\mathrm{FeCrAl}$ installation in a commercial nuclear reactor in the Spring of 2018 [21]. For this first installation, tube segments of APMT (a powder metallurgy alloy) and C26M (a traditionally melted experimental alloy) will be used. The main differences between these two alloys is their $\mathrm{Cr}$ content and the method of fabrication.

\section{Mitigation measures to neutron absorption and tritium release}

By its own nature, $\mathrm{FeCrAl}$ alloys offer a larger parasitic neutron absorption compared to zirconium alloys $[6,7,22]$. Because FeCrAl alloys such as APMT and C26M are stronger than zirconium alloys at near $400^{\circ} \mathrm{C}$, the $\mathrm{FeCrAl}$ material for the cladding can be made approximately half the thickness of the current zirconium alloys (Figs. 6-8). The thinning of the wall will increase the volume of the uranium dioxide pellet inside the rod.

Additional design changes (such as the fuel channel), may be required to meet bundle design requirements, further impacting fuel cycle economics. However, potential mitigation strategies have been identified that may partially or fully offset these neutron penalties. Such mitigation strategies include alternate materials (e.g. silicon carbide composite channel materials), higher allowable heat generation rates, as well as relaxation of regulatory requirements due to much improved fuel cladding performance under normal/off-normal, design basis and beyond design basis accident conditions, which in turn will result in improved economics of plant operation.

A second issue that requires resolution is the potential to increase release of tritium into the coolant. EPRI reported that when austenitic stainless steel cladding was used for power generation the amount of tritium in the coolant water was approximately 10 times higher than when zirconium cladding was used [23]. Also since $\mathrm{FeCrAl}$ are ferritic (bcc) in nature, it can be inferred that the diffusion of tritium through the cladding wall into the 

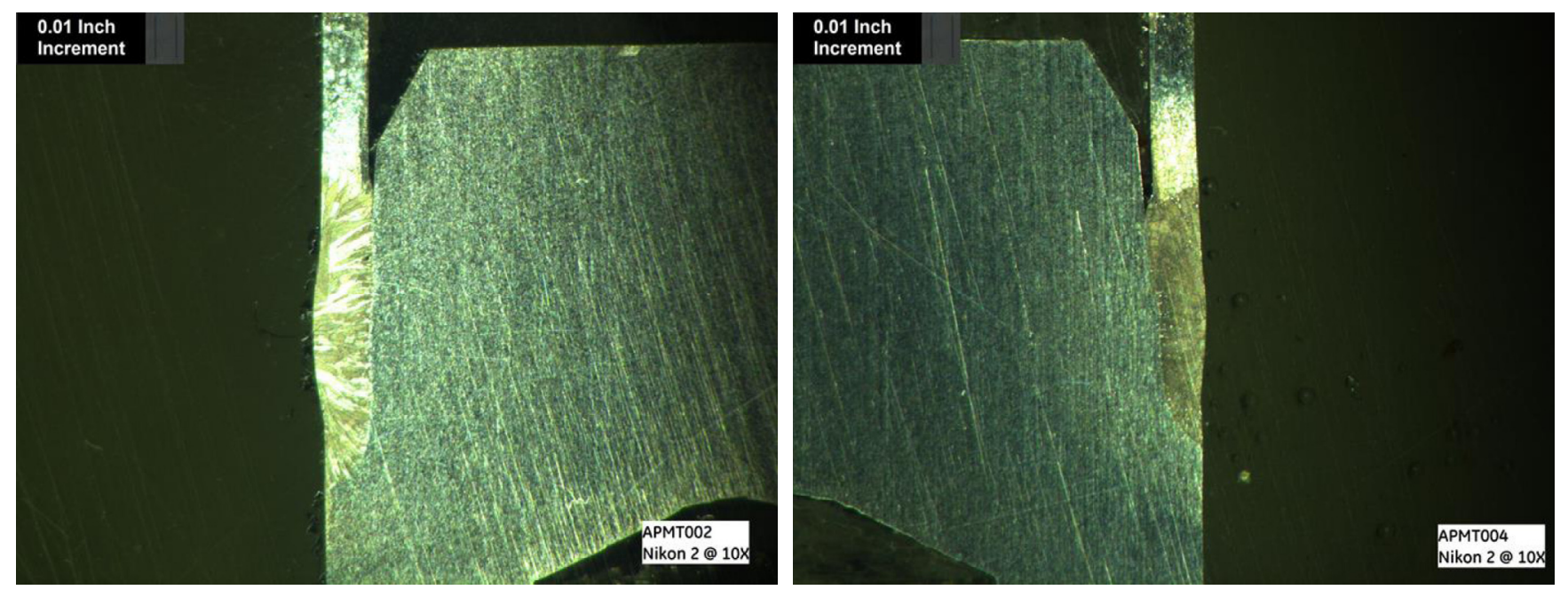

Fig. 7. Thin walled tubes of APMT welded to APMT end caps using industrial production setting.
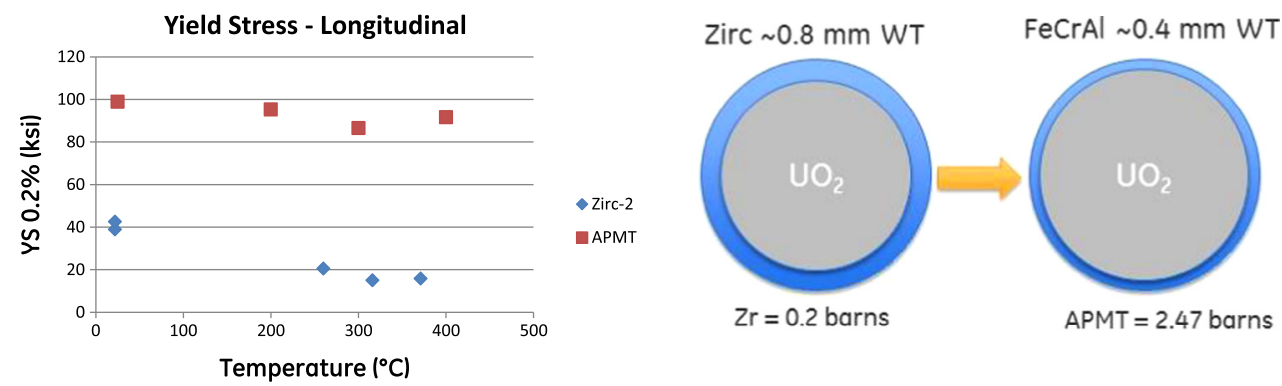

Fig. 8. Mechanical and neutron absorption properties of APMT and Zircaloy-2.

\section{Non-pre-oxidized FeCrAl}

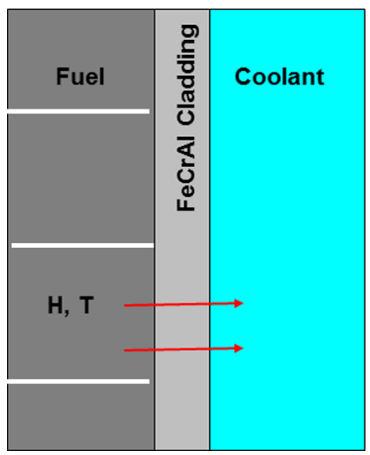

Fig. 9. Schematic representation how an alumina layer will impede the diffusion of tritium from the fuel to the coolant.

coolant could be even higher than when the austenitic (fcc) material was used. One potential mitigation strategy, currently under investigation, is the formation of an alumina layer (or other type of permeation barrier) in the ID and/or OD of the cladding [24]. A thin alumina layer (Figs. 4 and 9) in the ID of the cladding will significantly reduce the hydrogen permeation from the fuel to the coolant [25]. It has been shown that not only alumina would reduce permeation of tritium from the fuel to the coolant, other oxides will also reduce hydrogen or tritium permeation $[26,27]$.

\section{Final remarks}

Worldwide, there are several proposed concepts of ATF to make power rectors safer to operate. [28] One of the evolutionary and more near term for implementation concepts is to use $\mathrm{FeCrAl}$ for the cladding of $\mathrm{UO}_{2}$ fuel [28]. As mentioned before, the positive attributes of $\mathrm{FeCrAl}$ is its versatility regarding the corrosion resistance under both normal operation conditions $\left(\sim 300^{\circ} \mathrm{C}\right.$ water $)$ and accident conditions in superheated steam $\left(T>1100^{\circ} \mathrm{C}\right)$. Figure 10 illustrates the versatility of $\mathrm{FeCrAl}$ and its ability to react to the environment using the right oxide for protection. Aluminum does not participate in the protection of $\mathrm{FeCrAl}$ under normal operation conditions, only chromium is necessary if an accident never happens. This is the same as the protection mechanism of type 304SS or Inconel 600 . Aluminum is sine qua non for the alloy only in the case of an accident. For most reactors, aluminum would just ride along and will never be needed. If a loss of coolant accident happens, as the temperature of the cladding increases over $1100^{\circ} \mathrm{C}$, the chromium oxide would volatilize and alumina will form on its place protecting the alloy until the melting point of $\mathrm{FeCrAl}$. If quenching of the reactor is allowed 
Surface Oxide Evolution on APMT FeCrAl

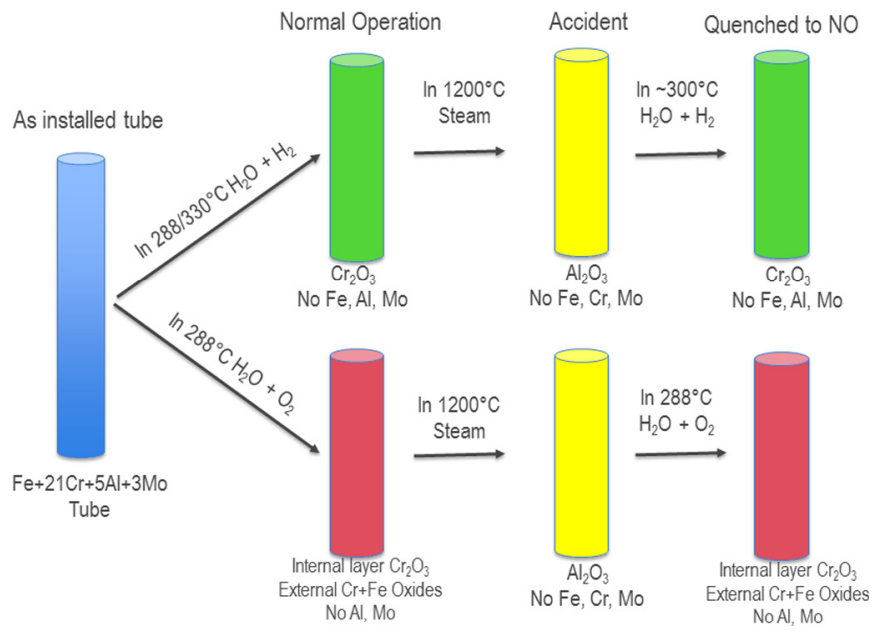

Fig. 10. Schematic representation how aluminum and chromium in $\mathrm{FeCrAl}$ react to normal operation conditions and accident conditions. Cr is beneficial only for normal operation conditions and $\mathrm{Al}$ only for superheated steam accident conditions.

below the melting point, the alumina on the surface of the alloy eventually will dissolve in the $300^{\circ} \mathrm{C}$ water and a chromium oxide will form in its place protecting the alloy for years to come. The evolution process between chromia and alumina on the surface of $\mathrm{FeCrAl}$ is reversible, from chromia to alumina and from alumina to chromia [29].

\section{Conclusions}

- The proposed accident tolerant fuel (ATF) design concept utilizes a FeCrAl alloy material such as APMT or $\mathrm{C} 26 \mathrm{M}$ as fuel rod cladding in combination with uranium dioxide $\left(\mathrm{UO}_{2}\right)$ fuel pellets, resulting in a fuel assembly that leverages the performance of existing present LWR fuel assembly designs and infrastructure with improved accident tolerance.

- The use of FeCrAl will greatly improve the safety of plant operation by putting a tougher primary barrier between the radioactive elements in the fuel and the coolant.

- Under accident conditions, FeCrAl alloys are orders of magnitude more resistant to reaction with superheated steam than zirconium, generating less combustible hydrogen and lower heat of reaction.

- FeCrAl alloys are less transparent to neutrons than zirconium alloys, therefore the cladding wall needs to be in the order of $400 \mu \mathrm{m}$. Tritium release into the coolant can be minimized by the presence of oxides on the surface of the tubes.

The financial support of GE Hitachi nuclear and global nuclear fuels is gratefully acknowledged. This material is based upon work supported by the Department of energy [National nuclear security administration] under Award Number DE-NE0008221. This report was prepared as an account of work sponsored by an agency of the United States Government. Neither the United States Government nor any agency thereof, nor any of their employees makes any warranty, express or implied, or assumes any legal liability or responsibility for the accuracy, completeness, or usefulness of any information, apparatus, product, or process disclosed, or represents that its use would not infringe privately owned rights. Reference herein to any specific commercial product, process or service by trade name, trademark, manufacturer, or otherwise does not necessarily constitute or imply its endorsement, recommendation, or favoring by the United States Government or any agency thereof. The views and opinions of authors expressed herein do not necessarily state or reflect those of the United States Government or any agency thereof.

\section{References}

1. R.B. Rebak, Nuclear application of oxide dispersion strengthened and nano-featured alloys: an introduction, JOM 66, 2424 (2014)

2. Nuclear energy institute (NEI), www.nei.org (retrieved: 2017/19/01)

3. US nuclear regulatory commission, Fact sheet on nuclear reactor risk, http://www.nrc.gov/reading-rm/doc-collec tions/fact-sheets/reactor-risk.html

4. N. Sridhar, Risk assessment of corrodible systems-an overview, Mater. Perform. 50, 32 (2011)

5. IAEA, International Atomic Energy Agency, in Risk management: a tool for improving nuclear power plant performance, TECDOC-1209, Vienna (2001)

6. S.J. Zinkle, K.A. Terrani, J.C. Gehin, L.J. Ott, L.L. Snead, Accident tolerant fuels for LWRs: a perspective, J. Nucl. Mater. 448, 374 (2014)

7. R.B. Rebak, Alloy selection for accident tolerant fuel cladding in commercial light water reactors, Metall. Mater. Trans. E 2E, 197 (2015)

8. R.B. Rebak, K.A. Terrani, W.P. Gassmann, J.B. Williams, K.L. Ledford, Improving nuclear power plant safety with $\mathrm{FeCrAl}$ alloy fuel cladding materials research society fall meeting, MRS Adv. 2, 1217 (2017)

9. S.M. Bragg-Sitton, M. Todosow, R. Montgomery, C.R. Stanek, R. Montgomery, W.J. Carmack, Metrics for the technical performance evaluation of light water reactor accident tolerant fuel, Nucl. Technol. 195, 111 (2016)

10. K.R. Robb, Analysis of the FeCrAl accident tolerant fuel concept benefits during BWR station blackout accidents, in Proc. of NURETH-16, Chicago, IL, USA, 2015

11. EPRI, Evaluation of expected behavior of LWR stainless steel-clad fuel in long-term dry storage (Electric Power Research Institute, Palo Alto, CA, 1996)

12. P.M. Ahmedabadi, G.S. Was, Stress corrosion cracking of ferritic-martensitic steels in simulated boiling water reactor environment, Corrosion 72, 66 (2016)

13. R.B. Rebak, N.R. Brown, K.A. Terrani, Assessment of advanced steels as accident tolerant fuel cladding for commercial light water reactors, in Paper 227, 17th International Conference on Environmental Degradation of Materials in Nuclear Power Systems-Water Reactors, Ottawa, Ontario, Canada (Canadian Nuclear Society, Toronto, 2015)

14. D.D. Ellis, R.B. Rebak, Passivation characteristics of ferritic stainless materials in simulated reactor environments, in Paper C2016-7452, Corrosion 2016 (NACE International, Houston, TX, 2016), p. 7452

15. R.B. Rebak, M. Larsen, Y.-J. Kim, Characterization of oxides formed on iron-chromium-aluminum alloy in simulated light water reactor environments, Corr. Rev. 35, 177 (2017) 
16. T. Terachi, K. Arioka, Characterization of oxide film behaviors on 316 stainless steels in high-temperature water-influence of hydrogen and oxygen considerations for initiation of SCC, in Paper 06608, Corrosion 2006 Conference and Exposition (NACE International, Houston, TX, 2006)

17. M. Da Cunha Belo, M. Walls, N.E. Hakiki, J. Corset, E. Picquenard, G. Sagon, D. Noel, Composition, Structure and properties of the oxide films formed on the stainless steel $316 \mathrm{~L}$ in a primary type PWR environment, Corros. Sci. 40, 447 (1998)

18. Y.-J. Kim, F. Wagenbaugh, T.B. Jurewicz, R.J. Blair, R.B. Rebak, Environmental behavior of light water reactor accident tolerant candidate cladding materials under design conditions, in Paper C2015-5-817, Corrosion 2015 (NACE International, Houston, TX, 2015)

19. K. Sakamoto, M. Hirai, S. Ukai, A. Kimura, A. Yamaji, K. Kusagaya, T. Kondo, S. Yamashita, Overview of japanese development of accident tolerant FeCrAl-ODS fuel claddings for BWRs, in WRFPM 2017 Conference, Jeju Island (2017)

20. F. Nagase, K. Sakamoto, S. Yamashita, Performance degradation of candidate accident-tolerant cladding under corrosive environment, Corros. Rev. 35, 129 (2017)

21. R.E. Stachowski, R. Fawcett, R.B. Rebak, W.P. Gassmann, J.B. Williams, K.A. Terrani, Progress of GE Development of accident tolerant fuel FeCrAl cladding, in Paper A-287, WRFPM 2017 Conference in Jeju Island, Republic of Korea (2017)
22. N.M. George, K. Terrani, J. Powers, A. Worrall, I. Maldonado, Neutronic analysis of candidate accident-tolerant cladding concepts in pressurized water reactors, Ann. Nucl. Energy 75, 703 (2015)

23. EPRI, An Evaluation of Stainless Steel Cladding for use in Current Design LWRS, Report NP-2642, Section 4 Tritium Release from Stainless steels, 1982 (http://www.epri.com/ abstracts $/$ Pages $/$ ProductAbstract.aspx?ProductId $=$ NP2642)

24. R.B. Rebak, Y.-J. Kim, Hydrogen diffusion in FeCrAl alloys for light water reactors cladding applications, in Paper PVP2016-63164, 2016 ASME PVP Conference, MF-7 Materials and Technologies for Nuclear Power Plants Vancouver, $B C$ (2016)

25. D. Levchuk, H. Bolt, M. Döbeli, S. Eggenberger, B. Widrig, J. Ramm, Al-Cr-O thin films as an efficient hydrogen barrier, Surf. Coat. Technol. 202, 5043 (2008)

26. R.A. Strehlow, H.C. Savage, The permeation of hydrogen isotopes through structural metals at low pressures and through metals with oxide film barriers, Nucl. Technol. 22, $127(1974)$

27. E.H. Van Deventer, V.A. Maroni, Hydrogen permeation characteristics of some Fe-Cr-Al alloys, J. Nucl. Mater. 113, $65(1983)$

28. N. Waeckel, Using E-ATF in nuclear power plants: utility perspectives, in Paper IA-00\%, WRFPM 2017, Jeju Island, Korea (2017)

29. R.B. Rebak, J. Met., in print

Cite this article as: Raul B. Rebak, Iron-chrome-aluminum alloy cladding for increasing safety in nuclear power plants, EPJ Nuclear Sci. Technol. 3, 34 (2017) 